\title{
The importance of occlusal force measurement in orthognathic surgery - A pilot study
}

\author{
Duarte $F^{1}$, Silva $J^{2}$, Hopper $C^{3}$, \\ Hunt $N^{3}$ \\ Affiliations: \\ 1. CEO and Clinical Director of Clitrofa - Trofa, \\ Portugal \\ 2. Instituto Superior de Saúde ISAVE, Portugal \\ 3. UCL Eastman Dental Institute, London, UK \\ Corresponding author: \\ Fernando Duarte \\ fduarte@clitrofa.com
}

\section{ABSTRACT}

Purpose: This pilot investigation was designed to apply several, newly developed and more sophisticated methods of measuring muscle structure and function in a situation where adaptation of muscle is pivotal to the success of a therapeutic approach. Materials and Methods: Patients attending the combined orthodontic/orthognathic surgery clinic at the Clitrofa - Centro Médico, Dentário e Cirúrgico, in Trofa - Portugal were tested according to the protocol of Bite force and occlusal contact area were simultaneously measured with Bite Training Machine and Occlusal Force Diagnostic System. An Experimental design used for the measurement of occlusal force. The study involved the contribution of two independent examiners that measured the bite pressure (psi) in five different FSS sensors at three different time moments. A combination of different parametric tests has been used to compare the different experimental variables.

Results: Neither the variation of examiner, nor the variations of time have shown to influence the bite pressure (psi). In contrast, the occlusal force measurement system developed has shown a high level of sensitivity due to the distribution of the five FSS sensors in the horseshoe-shaped form. A three-pressure region model fits the experimental data shown in this study, comprising a low-pressure region located in the anterior part of the dental arch, a medium-pressure region in the medial part of the dental arch and an high-pressure region located in the posterior part of the dental arch.

Conclusions: The piezoelectric sensors used in the present study have shown high reproducibility of measurement. Due to the recent miniaturization of FSS sensors, the authors are developing new occlusal force measurement systems comprising a higher number of piezoelectric sensors, with the objective of attaining even higher sensitivity of measurement throughout the different region of the dental arches.

\section{KEYWORDS}

Orthognathic surgery, massseter muscle, occlusal force measurement 


\section{INTRODUCTION}

One of the main purposes of orthognathic treatment in patients with a dentofacial deformity is to improve masticatory function as well as aesthetics. Numerous studies have documented masticatory function, for example: including bite force, occlusal contact and masticatory efficiency, in patients with mandibular prognathism before and after orthognathic surgery ${ }^{1-13}$ but few reports compared the results with those in controls with normal occlusion. ${ }^{1,3,6-9,12,13}$ There have also been few studies that involved evaluation of these parameters at the initial medical consultation for patients undergoing orthognathic surgery. ${ }^{14,15}$ No reports were found that simultaneously evaluated the relationships between bite force, occlusal contact and masticatory efficiency in patients with mandibular prognathism and in controls with normal occlusion. Previously, changes in bite force and occlusal contact before and after orthognathic surgery were investigated and presented using the T-Scan system ${ }^{\mathrm{TM}}$ (Tekscan, USA). ${ }^{3}$ This system is convenient and simple but is poor regarding reproducibility and quantification. Recently, a simple method for occlusal analysis, the Dental Prescale ${ }^{\mathrm{TM}}$ system (Fuji Photo Film Co., Japan), has been developed. This is a computerized system intended to assist occlusal analysis by providing information as to the magnitude of the bite force and the distribution of occlusal contacts. The system is capable of simultaneously measuring these parameters for teeth separated by less than $10 \mathrm{~mm}$ and has potential for research in centric occlusion. It is a horseshoe-shaped thin film that consists of two layers: a layer of microcapsules containing colour-forming materials and a layer of colour-developing materials. The colour-developing materials, producing a red colour in the contact area when a force is generated, absorb the released colour-forming materials. The Dental Prescale ${ }^{\mathrm{TM}}$ system has already been used for analysing occlusion in dentures ${ }^{16,17}$, dental implants $^{18}$ and orthognathic surgery. 7,8 Many methods for the quantitative measurement of masticatory efficiency have been introduced, but none stands out as ideal. Spectrophotometric methods for the evaluation of masticatory efficiency have been reported, involving measurement of the absorbance of adenosine triphosphate (ATP) granules., 6,12 This technique shows accuracy and reproducibility but is complicated. A new chewing-gum system has been developed for the estimation of masticatory function by the Meiji Chewing Gum Corporation. It utilizes a phloxine-sodium bicarbonate reaction and measures a chromatic coordinate as an indicator. This low-adhesive colour developing chewing-gum system has already been used for analysing the masticatory function of dental implants ${ }^{19}$ and dentures ${ }^{20}$.

The authors decided to build their own Occlusal Force Diagnostic System and test it on a group of patients.

\section{OCCLUSAL FORCE DIAGNOSTIC SYSTEM}

\section{A) Sensors}

The FS Series sensors provide precise reliable force sensing performance in a compact commercial grade package. The sensor features a proven sensing technology that uses a specialized piezoresistive micromachined silicon sensing element. The low power, unamplified, uncompensated Wheatstone bridge circuit design provides inherently stable $\mathrm{mV}$ outputs over the force range.

Force sensors operate on the principle that the resistance of silicon-implanted piezoresistors will increase when the resistors flex under any applied force. The sensor concentrates force from the applications, through the stainless-steel ball, directly to the silicon-sensing element. The amount of resistance changes in proportion to the amount of force being applied. This change in circuit resistance results in a corresponding $\mathrm{mV}$ output level change.

The stainless-steel ball provides mechanical stability and is adaptable to a variety of applications. The FSS sensor delivered 20 million operations in Mean Cycles to Failure (MCTF) reliability testing at $50^{\circ} \mathrm{C}\left[122^{\circ} \mathrm{F}\right]$. This test determines the number of possible sensor operations at full scale until failure. Various electric interconnects can accept prewired connectors, printed circuit board mounting, and surface mountings. The sensor design also provides a variety of mounting options that include mounting brackets, as well as application specific mounting requirements.

The typical applications of these sensors are medical infusion pumps, ambulatory non-invasive pump pressure, occlusion detection, kidney dialysis machines, load and compression sensing, variable tensions control, robotic end-effectors and wire bonding equipment.

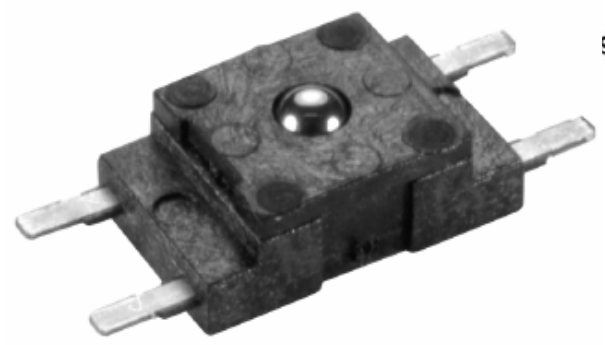

SENSOR PINOUT
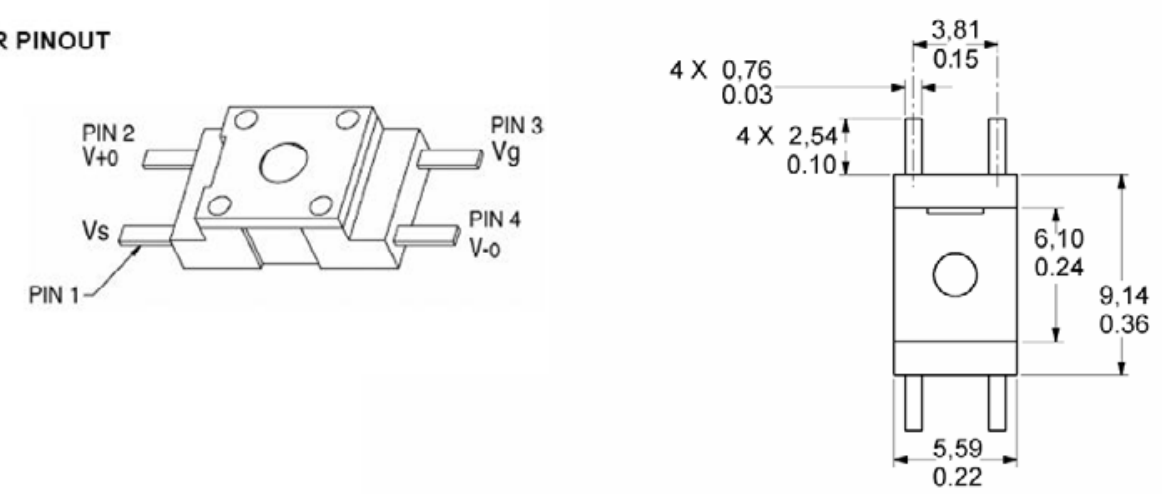

\section{Description of Sensor Circuit:}

Pin $1=$ Supply VS $(+)$, Pin $2=$ Output VO (+),

Pin $3=$ Gr ound Vg $(-)$, Pin $4=$ Output VO (-)

2. The force sensor may be powered by voltage or current. Maximum supply voltage is not to exceed 12 volts. Maximum supply current is not to exceed $1.6 \mathrm{~mA}$. Power is applied across Pin 1 and Pin 3 .

3. The sensor output should be measured as a differential voltage across Pin 2 and Pin 4 $(\mathrm{VO}=\mathrm{V} 2-\mathrm{V} 4)$. The output is ratiometric to the supply voltage. Shifts in supply voltage will cause shifts in output. Neither Pin 2 nor Pin 4 should be tied to ground or voltage supply.

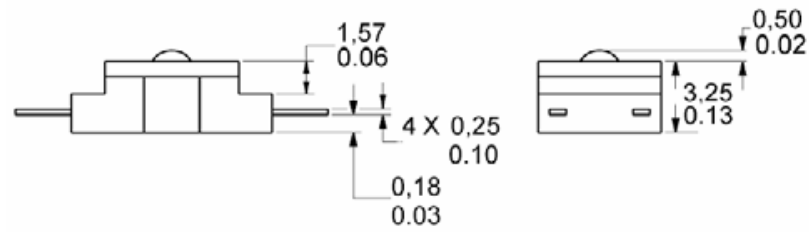

Figure 1. Schematic illustration of the FSS Sensor, sensor circuit and mounting 


\section{B) Distribution}

The occlusal force diagnostic system has been developed between CEiiA - Centre of Engineering and Product Development in Oporto and the UCL, Eastman Dental Institute in London. The first idea was to place seven sensors distributed by the dental arch in a horseshoe-shaped form designated by bite force, but because of the sensors dimensions was decided to place only five. One sensor was for the anterior teeth (central and lateral incisors), two sensors for the canine and first pre-molar and another two sensors for the second pre-molar and first molar. The objective of this sensor's distribution was to make measurements of occlusal contact areas and occlusal pressures individually and in total. The sensors were connected between them, and the cables connected to a transducer that shows the digital reading in kilograms.

During the process of development was felt interesting to have the five sensors reading at the same time. To achieve this several changes were introduced, namely the inclusion of five digital screens, each one corresponding to one sensor, the construction of a portable suitcase able to accommodate all the occlusal diagnostic system and an on-off bottom. Each digital screen works with its own battery placed in the suitcase under a metal foil that cover all the electrical connections.

The dental arch in a horseshoe-shaped form was built by a superior and an inferior $3 \mathrm{~mm}$ height metal foil covered by a hard resin, with the following intra-oral measures: $63 \mathrm{~mm}$ total width, $62 \mathrm{~mm}$ total length, $15 \mathrm{~mm}$ width in the anterior occlusal contact area, $19 \mathrm{~mm}$ width in the posterior occlusal contact area, $30 \mathrm{~mm}$ anterior height and $15 \mathrm{~mm}$ posterior height. The dental arch dimensions were based on most of the dental arches studied during the improvement process.
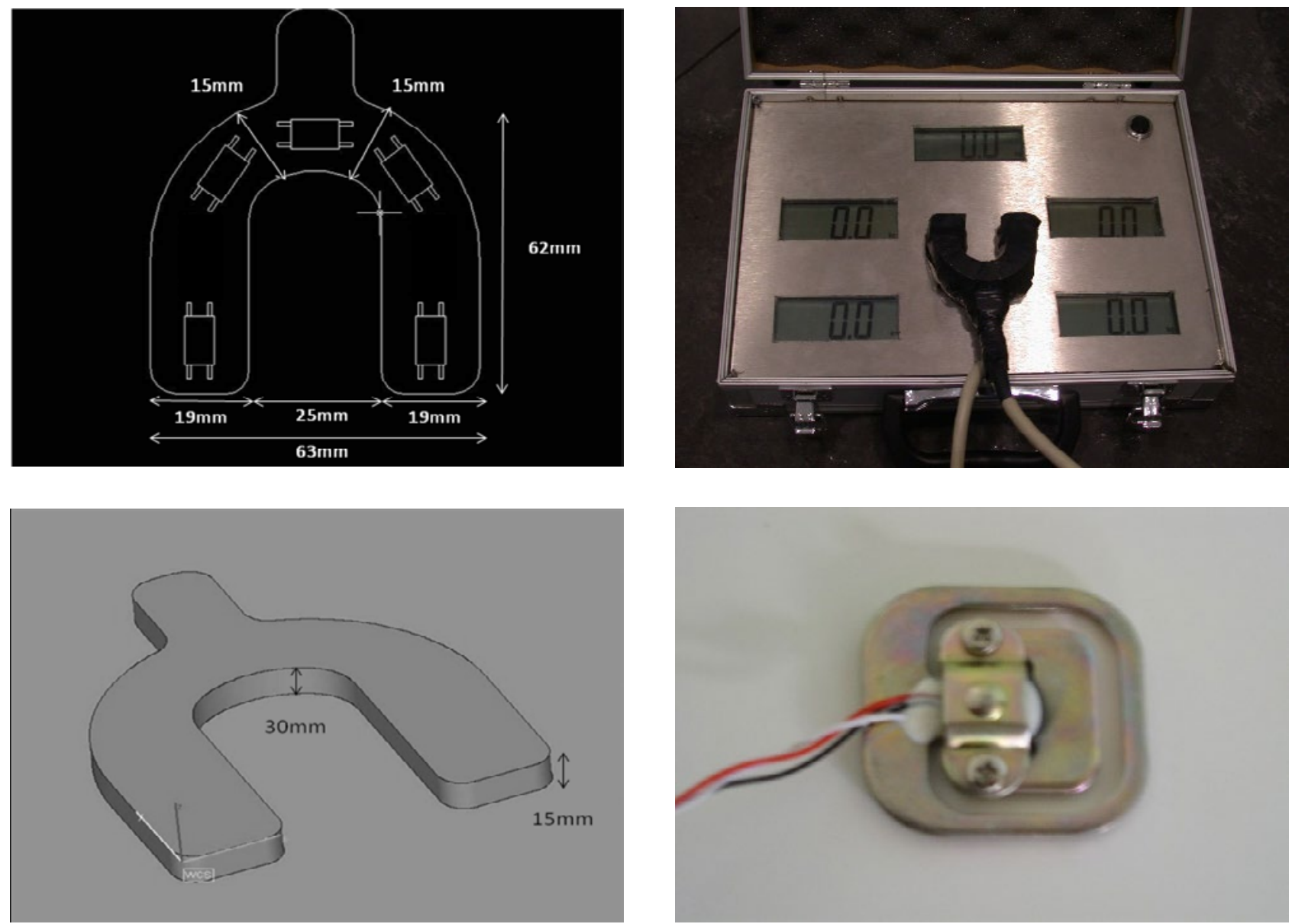

Figure 2. Components of the Occlusal Force Diagnostic System: FSS sensor, Sensors distribution, Occlusal platform dimensions and Digital screens 


\section{C) Compatibility}

It is very important to ensure compatibility between the pressure or force sensor and the application in which it is used. The following should be considered before a sensor selection is made: (1) material; (2) chemicals; (3) concentration; (4) temperature; (5) exposure time; (6) type of exposure; (7) criteria for failure; and (8) general information such as application environment, protection of the device, and other foreign substances in the area.

\section{D) Repeatability Test}

The occlusal force diagnostic system was placed between the upper and lower dental arch, and the subjects were instructed to bite as forcefully as possible for about 3 seconds. The values were registered (TO) and the procedure was repeated after 10 minutes (T1), and after 1 month (T2). In the proposed repeatability test, the bite force and occlusal pressure were measured in 30 consecutive patients twice by two different observers.

The five sensors were distributed in the following order, the readings were in kilograms:

- Sensor A: right maxillary second pre-molar and right maxillary first molar between 1st and 4th quadrants,

- Sensor B: right maxillary canine and right maxillary first premolar between 1st and 4th quadrants,

- Sensor C: right and left maxillary central incisors and right and left maxillary lateral incisors area,

- Sensor D: left maxillary second pre-molar and left maxillary first molar between 2nd and 3rd quadrants,

- Sensor E: left maxillary canine and left maxillary first pre-molar between 2nd and 3rd quadrants,

\section{E) Bite Training Machine}

In order to provide adequate training to the patients and teach how to bite in the same way during the study a bite training machine was developed. The major components of this new machine were: a dynamometer, a force indicator and an occlusal contact area indicator.

The occlusal contact area was built in a hard-photosensitive resin with a similar strength of the occlusal force diagnostic system, and two springs were placed to allow movement return. The dynamometer was ordered from Mitutoyo ${ }^{\mathrm{TM}}$ (Mitutoyo Corporation, USA) and ensure that the patient was biting hard enough to see the reading.

The occlusal contact area indicator was placed between the upper and lower dental arch, and the subjects were instructed to bite as forcefully as possible for about 3 seconds. The values were visualized in the dynamometer and the procedure was repeated after 10 minutes until the patient felt comfortable.
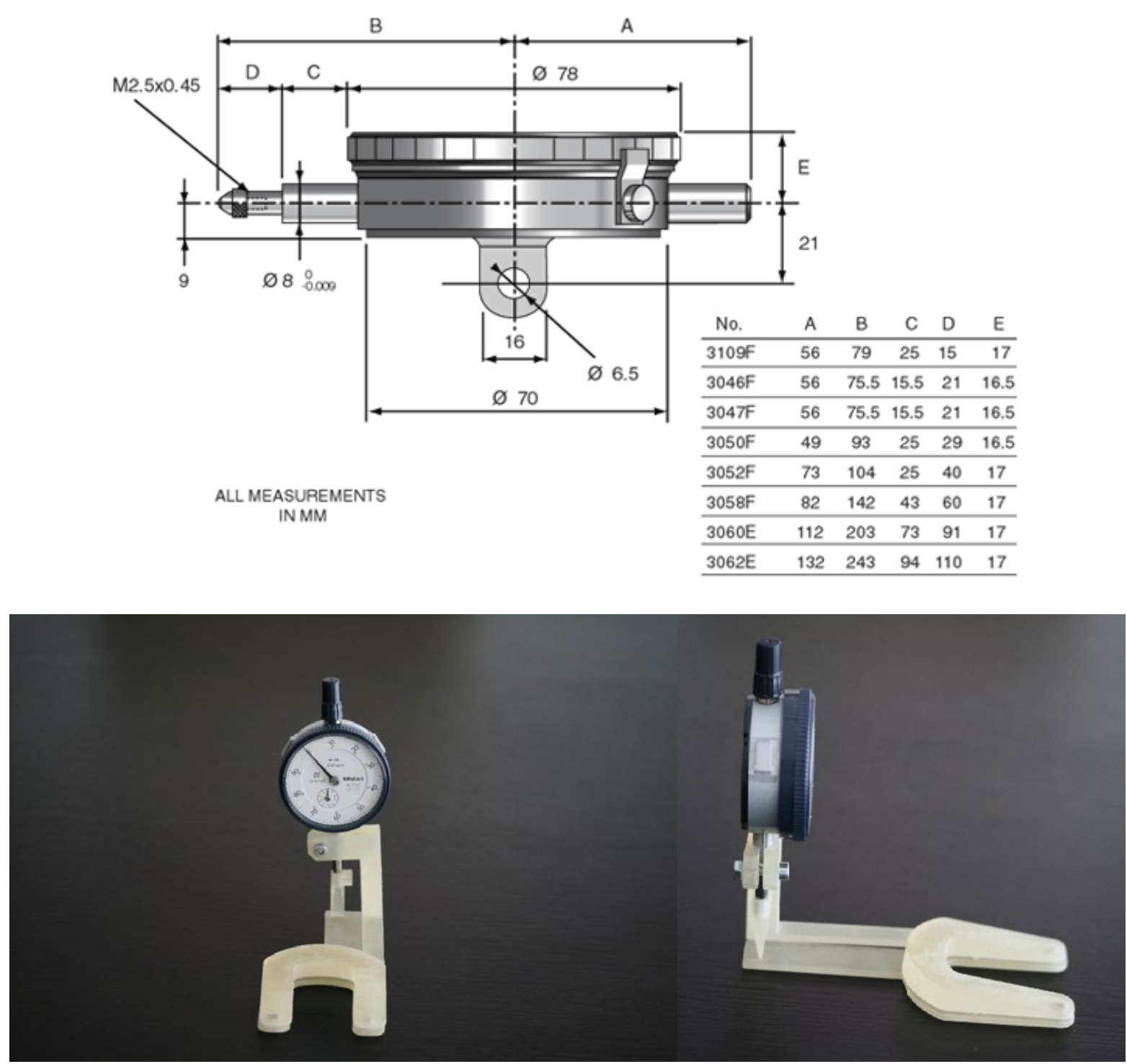

Figure 3. Major components of the Bite Training Machine: dynamometer, force indicator and occlusal area 


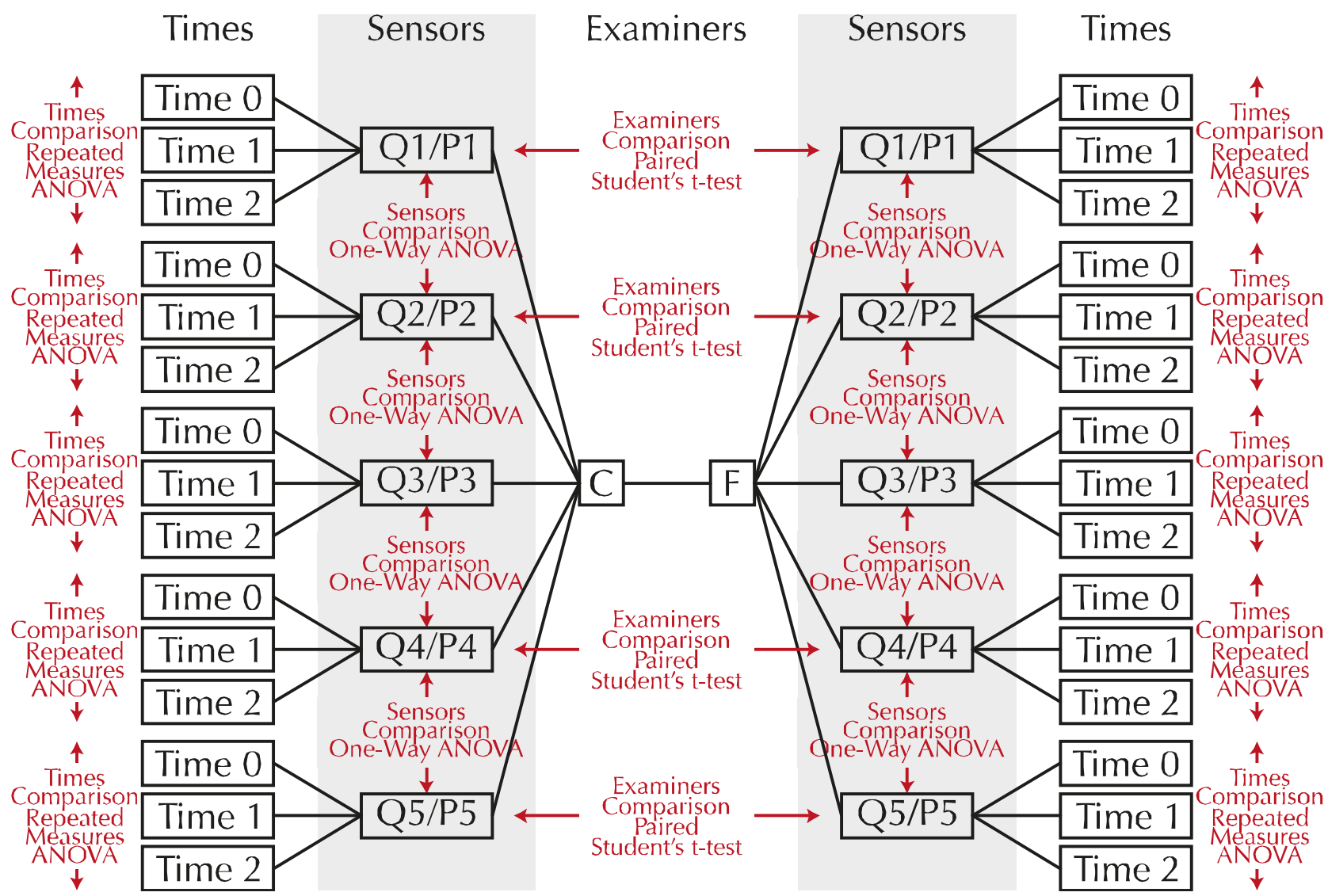

Figure 4. Experimental design used for the measurement of occlusal force. The study involved the contribution of two independent examiners (F and $\mathrm{C}$ ), that measured the bite pressure (psi) in five different FSS sensors (Q1/P1, Q2/P2, Q3/P3, Q4/P4 and Q5/P5) at three different time moments (Time 0, Time 1 and Time 2).

\section{MATERIALS AND METHODS}

Patients attending the combined orthodontic/orthognathic surgery clinic at the Clitrofa - Centro Médico, Dentário e Cirúrgico, in Trofa - Portugal were tested according to the following protocol:

a) Bite Training Machine: The occlusal contact area indicator was placed between the upper and lower dental arch, and the subjects were instructed to bite as forcefully as possible for about 3 seconds. The values were visualized in the dynamometer and the procedure was repeated after 10 minutes until the patient felt comfortable.

b) Occlusal Force Diagnostic System: The system was placed between the upper and lower dental arch, and the subjects were instructed to bite as forcefully as possible for about 3 seconds. The values were registered (TO) and the procedure was repeated after 10 minutes (T1), and after 1 month (T2). In the proposed repeatability test, the bite force and occlusal pressure were measured in 30 consecutive patients twice by two different observers.

A combination of different parametric tests has been used to compare the different experimental variables. The experimental design devised for this study is depicted in Figure 4, comprising a combination of different examiners, sensors and times of measurement.

\section{Comparison A - Testing the Differences between Examiners ( $F$ versus $C$ )}

Research question: Are there any differences in the mean bite pressure (psi) measured by Examiner $\mathrm{F}$ and Examiner $\mathrm{C}$ in the same experimental conditions?

$\mathrm{HO}$ : There are no differences in the mean bite pressure (psi) measured by Examiner $\mathrm{F}$ and Examiner $\mathrm{C}$ in the same experimental conditions.

$\mathrm{H1}$ : There are differences in the mean bite pressure (psi) measured by Examiner $F$ and Examiner $C$ in the same experimental conditions.

\section{Comparison B - Testing the Differences between Times (TO versus $\mathrm{T} 1$ versus $\mathrm{T} 2$ )}

Research question: Are there any differences in the mean bite pressure (psi) measured between moments Time 0, Time 1 and Time 2 in the same experimental conditions?

$\mathrm{HO}$ : There are no differences in the mean bite pressure (psi) measured at moments Time 0, Time 1 and Time 2 in the same experimental conditions.

$\mathrm{H1}$ : There are differences in the mean bite pressure (psi) measured at moments Time 0 , Time 1 and Time 2 in the same experimental conditions. 
Comparison C - Testing the Differences between Sensors ( $Q 1 / P 1$ versus $Q 2 / P 2$ versus $Q 3 / P 3$ versus $Q 4 / P 4$ versus Q5/P5)

Research question: Are there any differences in the mean bite pressure (psi) measured by sensors Q1/P1, Q2/P2, Q3/P3, Q4/P4 and Q5/P5 in the same experimental conditions?

$\mathrm{HO}$ : There are no differences in the mean bite pressure (psi) measured by sensors Q1/P1, Q2/P2, Q3/P3, Q4/P4 and Q5/P5 in the same experimental conditions.

$\mathrm{H} 1$ : There are differences in the mean bite pressure (psi) measured by sensors Q1/P1, Q2/P2, Q3/P3, Q4/P4 and Q5/P5 in the same experimental conditions.

\section{RESULTS}

Table 1 presents the experimental data for the measurement of mean bite pressure (psi), as well as its SD and variance values.

Table 1. Values of bite pressure (psi) measured at the different experimental conditions shown in Figure 4.

\begin{tabular}{|c|c|c|c|}
\hline Variable & Mean (psi) & SD (psi) & Variance \\
\hline P1_F_T0 & 52,567 & 38,264 & 1464,116 \\
\hline P1_F_T1 & 53,067 & 38,224 & 1461,099 \\
\hline P1_F_T2 & 54,033 & 39,063 & 1525,895 \\
\hline P1_C_TO & 53,300 & 39,034 & 1523,666 \\
\hline P1_C_T1 & 53,800 & 39,284 & 1543,269 \\
\hline P1_C_T2 & 53,733 & 39,559 & 1564,892 \\
\hline P2_F_T0 & 36,567 & 28,877 & 833,909 \\
\hline P2_F_T1 & 36,500 & 28,567 & 816,052 \\
\hline P2_F_T2 & 36,967 & 28,823 & 830,792 \\
\hline P2_C_TO & 36,833 & 28,666 & 821,730 \\
\hline P2_C_T1 & 36,833 & 28,680 & 822,557 \\
\hline P2_C_T2 & 37,133 & 29,180 & 851,499 \\
\hline P3_F_T0 & 0,700 & 2,667 & 7,114 \\
\hline P3_F_T1 & 0,700 & 2,667 & 7,114 \\
\hline P3_F_T2 & 0,667 & 2,537 & 6,437 \\
\hline P3_C_TO & 0,700 & 2,667 & 7,114 \\
\hline P3_C_T1 & 0,700 & 2,667 & 7,114 \\
\hline P3_C_T2 & 0,667 & 2,537 & 6,437 \\
\hline P4_F_T0 & 28,933 & 24,996 & 624,823 \\
\hline P4_F_T1 & 29,567 & 25,117 & 630,875 \\
\hline P4_F_T2 & 29,433 & 24,897 & 619,840 \\
\hline P4_C_TO & 29,400 & 25,125 & 631,283 \\
\hline P4_C_T1 & 29,867 & 24,926 & 621,283 \\
\hline P4_C_T2 & 29,600 & 24,926 & 619,913 \\
\hline P5_F_T0 & 67,933 & 37,300 & 1391,306 \\
\hline P5_F_T1 & 65,533 & 35,586 & 1266,395 \\
\hline P5_F_T2 & 66,700 & 36,174 & 1308,562 \\
\hline P5_C_T0 & 66,633 & 36,480 & 1330,792 \\
\hline P5_C_T1 & 66,400 & 35,953 & 1292,593 \\
\hline P5_C_T2 & 66,867 & 35,509 & 1260,878 \\
\hline
\end{tabular}




\section{Comparison A - Testing the Differences between}

\section{Examiners ( $\mathbf{F}$ versus $\mathbf{C}$ )}

The statistical comparison between examiners $\mathrm{F}$ and $\mathrm{C}$ regarding the measurement of mean bite pressure (psi) was performed using a Paired Student's t-test for the five different FSS sensors (Q1/P1, Q2/P2, Q3/P3, Q4/P4 and Q5/P5) at the three different time moments (Time 0, Time 1 and Time 2).

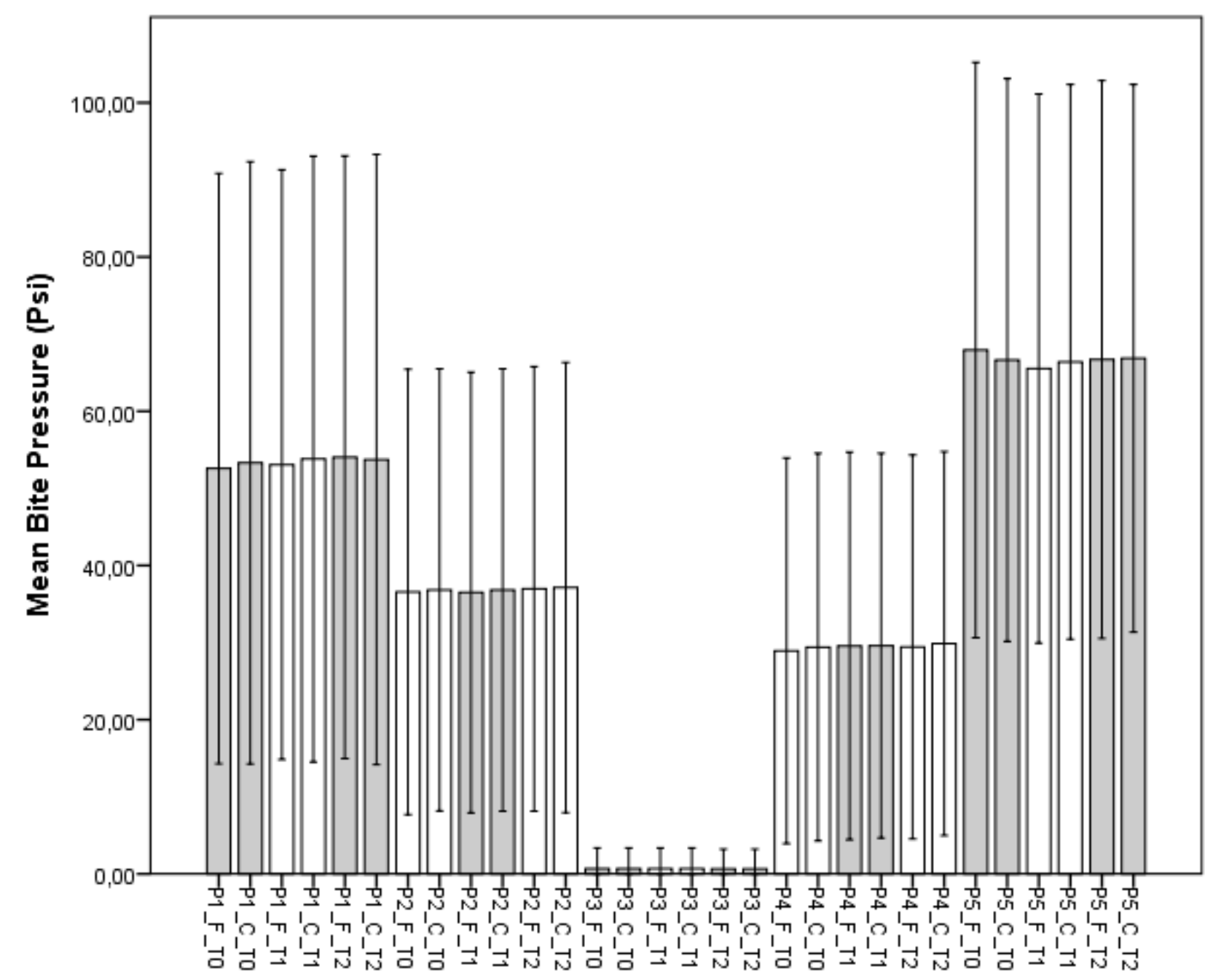

Figure 5. Mean bite pressure (psi) measured by Examiner F and Examiner $C$ in five different FSS sensors (Q1/P1, Q2/P2, Q3/P3, Q4/P4 and Q5/P5) at three different time moments (Time 0, Time 1 and Time 2). Error bars represent standard deviation values. 
Table 2. Statistical parameters obtained in the Paired Student's t-test for the comparison of examiners $\mathrm{F}$ and $\mathrm{C}$ when measuring the mean bite pressure (psi) in different experimental conditions

\begin{tabular}{|c|c|c|c|c|c|}
\hline Examiners Comparison & $\begin{array}{c}\text { Mean } \\
\text { Difference }\end{array}$ & $\begin{array}{l}\text { Standard } \\
\text { Deviation of } \\
\text { Differences }\end{array}$ & $\begin{array}{l}\text { Degrees of } \\
\text { Freedom (df) }\end{array}$ & $\begin{array}{c}\text { Test statistic } \\
\text { from Paired } \\
\text { t-test }\end{array}$ & $\begin{array}{l}\text { P-value from } \\
\text { Paired } t \text {-test }\end{array}$ \\
\hline Examiner $\mathrm{F}$ versus Examiner $\mathrm{C}, \mathrm{P} 1$, Time 0 & $-0,733$ & 4,185 & 29,000 & $-0,960$ & ,345 \\
\hline Examiner $\mathrm{F}$ versus Examiner $\mathrm{C}, \mathrm{P} 1$, Time 1 & $-0,733$ & 2,993 & 29,000 & $-1,342$ & , 190 \\
\hline Examiner $\mathrm{F}$ versus Examiner $\mathrm{C}, \mathrm{P} 1$, Time 2 & 0,300 & 2,200 & 29,000 & 0,747 &, 461 \\
\hline Examiner $\mathrm{F}$ versus Examiner $\mathrm{C}, \mathrm{P2}$, Time 0 & $-0,267$ & 1,437 & 29,000 & $-1,017$ & ,318 \\
\hline Examiner $\mathrm{F}$ versus Examiner $\mathrm{C}, \mathrm{P2}$, Time 1 & $-0,333$ & 2,040 & 29,000 & $-0,895$ & ,378 \\
\hline Examiner $\mathrm{F}$ versus Examiner $\mathrm{C}, \mathrm{P2}$, Time 2 & $-0,167$ & 3,302 & 29,000 & $-0,276$ & ,784 \\
\hline Examiner $\mathrm{F}$ versus Examiner $\mathrm{C}, \mathrm{P3}$, Time 0 & $-0,467$ & 1,961 & 29,000 & $-1,304$ & ,203 \\
\hline Examiner $\mathrm{F}$ versus Examiner $\mathrm{C}, \mathrm{P3}$, Time 1 & $-0,033$ & 1,426 & 29,000 & $-0,128$ & 899 \\
\hline Examiner $\mathrm{F}$ versus Examiner $\mathrm{C}, \mathrm{P3}$, Time 2 & $-0,433$ & 2,944 & 29,000 & $-0,806$ &, 427 \\
\hline Examiner $\mathrm{F}$ versus Examiner $\mathrm{C}$, P4, Time 0 & 1,300 & 3,164 & 29,000 & 2,251 & ,032 \\
\hline Examiner $\mathrm{F}$ versus Examiner $\mathrm{C}, \mathrm{P} 4$, Time 1 & $-0,867$ & 2,623 & 29,000 & $-1,810$ &, 081 \\
\hline Examiner $\mathrm{F}$ versus Examiner $\mathrm{C}, \mathrm{P4}$, Time 2 & $-0,167$ & 3,687 & 29,000 & $-0,248$ & 806 \\
\hline Examiner $\mathrm{F}$ versus Examiner $\mathrm{C}, \mathrm{P5}$, Time 0 & $-0,733$ & 4,185 & 29,000 & $-0,960$ & ,345 \\
\hline Examiner $\mathrm{F}$ versus Examiner $\mathrm{C}, \mathrm{P5}$, Time 1 & $-0,733$ & 2,993 & 29,000 & $-1,342$ & , 190 \\
\hline Examiner $\mathrm{F}$ versus Examiner $\mathrm{C}, \mathrm{P} 5$, Time 2 & 0,300 & 2,200 & 29,000 & 0,747 & ,461 \\
\hline
\end{tabular}

There are no significant differences in the mean bite pressure (psi) measured by Examiner $\mathrm{F}$ and Examiner $\mathrm{C}$, when the measurement is made in the same experimental conditions (Figure 5). Almost all experiments reveal $p$-values above the cutoff value of $0,05(p>0,05)$, which means that $\mathrm{H} 0$ proposition is valid (Table 2). The results obtained for sensor Q4/P4 at time 0 were not considered significant, as the general trend of data is the absence of statistical differences between examiners. Thus, it is concluded that the choice of examiner is not a variable that affects the mean bite pressure (psi) measured in any of the experimental conditions tested. 
Comparison B - Testing the Differences between Times ( $\mathrm{TO}$ versus $\mathrm{T1}$ versus T2)

The statistical comparison between the three time moments (Time 0, Time 1 and Time 2) regarding the measurement of mean bite pressure (psi) was performed using a Repeated Measures ANOVA for the five FSS sensors (Q1/P1, Q2/P2, Q3/P3, Q4/P4 and Q5/P5) and the different examiners F and C.

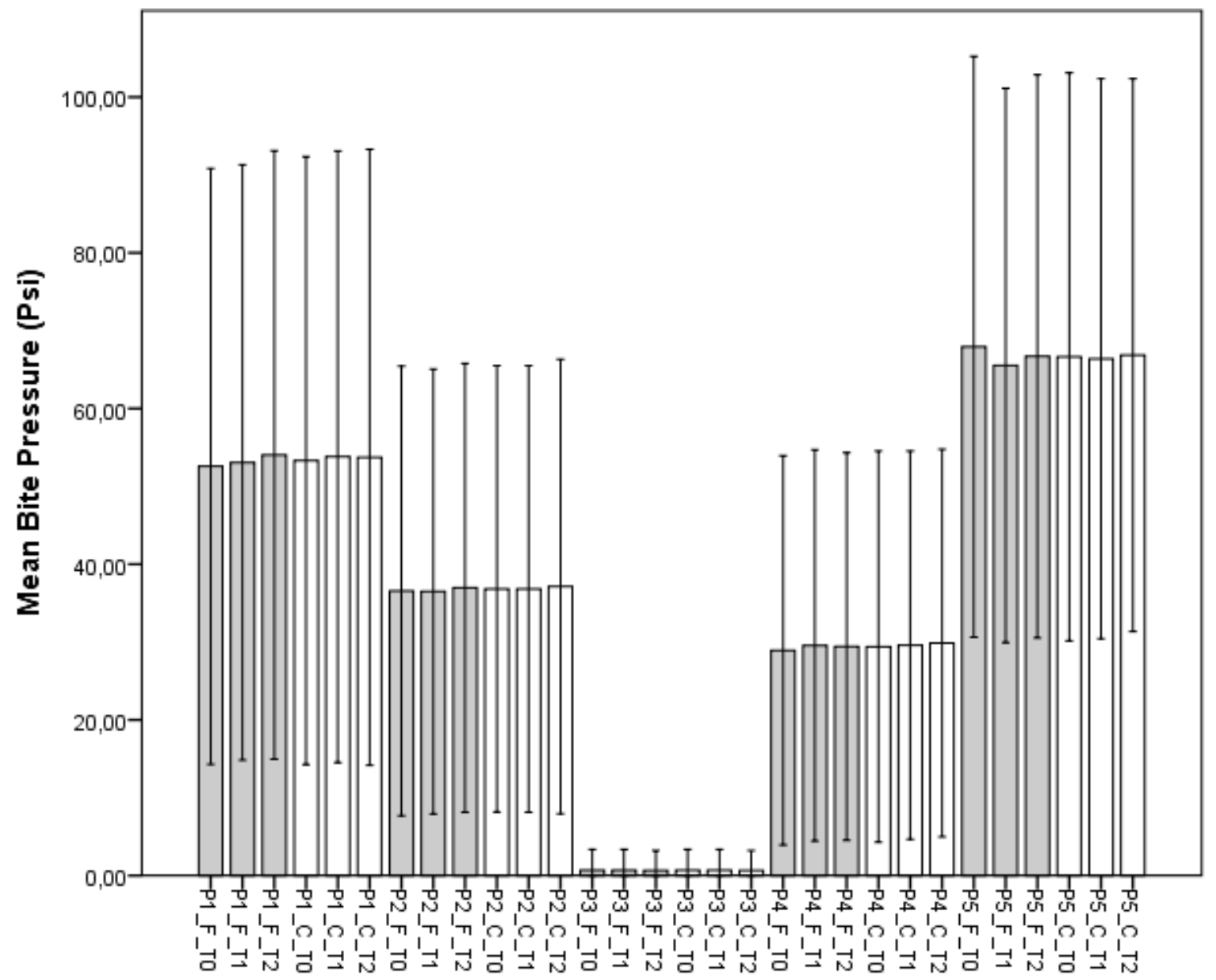

Figure 6. Mean bite pressure (psi) measured in three time moments (Time 0, Time 1 and Time 2) by Examiner F and Examiner $\mathrm{C}$ in five different FSS sensors (Q1/ P1, Q2/P2, Q3/P3, Q4/P4 and Q5/P5). Error bars represent standard deviation values.

Table 3. Statistical parameters obtained in the Repeated Measures ANOVA for the comparison of time moments (Time 0 , Time 1 and Time 2) when measuring the mean bite pressure (psi) in different experimental conditions.

\begin{tabular}{|l|c|c|c|}
\hline \multicolumn{1}{|c|}{ Times Comparison } & $\begin{array}{c}\text { Degrees of } \\
\text { Freedom (df) }\end{array}$ & $\begin{array}{c}\text { Test statistic } \\
\text { (F) }\end{array}$ & P-value (Sig) \\
\hline Time $\mathbf{0}$ vs Time 1 vs Time 2, Examiner F, P1 & 2,58 & $3,225(\mathrm{a})$ & $0,047(\mathrm{a})$ \\
\hline Time $\mathbf{0}$ vs Time 1 vs Time 2, Examiner C, P1 & 2,58 & 0,714 & 0,494 \\
\hline Time $\mathbf{0}$ vs Time 1 vs Time 2, Examiner F, P2 & 2,58 & 0,695 \\
\hline Time $\mathbf{0}$ vs Time 1 vs Time 2, Examiner C, P2 & 2,58 & 0,705 \\
\hline Time $\mathbf{0}$ vs Time 1 vs Time 2, Examiner F, P3 & 2,58 & 0,352 & 0,374 \\
\hline Time $\mathbf{0}$ vs Time 1 vs Time 2, Examiner C, P3 & 2,58 & 1,000 & 0,374 \\
\hline Time $\mathbf{0}$ vs Time 1 vs Time 2, Examiner F, P4 & 2,58 & 1,854 & 0,166 \\
\hline Time $\mathbf{0}$ vs Time 1 vs Time 2, Examiner C, P4 & 2,58 & 0,488 & 0,616 \\
\hline Time $\mathbf{0}$ vs Time 1 vs Time 2, Examiner F, P5 & 2,58 & $8,715(\mathrm{a})$ & $0,000(\mathrm{a})$ \\
\hline Time $\mathbf{0}$ vs Time $\mathbf{1}$ vs Time 2, Examiner C, P5 & 2,58 & 0,423 & 0,657 \\
\hline
\end{tabular}


There are no significant differences in the mean bite pressure (psi) measured at Time 0, Time 1 or Time 2, for the same Examiner ( $\mathrm{C}$ or $\mathrm{F}$ ) and the same Sensor (Q1/P1, Q2/P2, Q3/P3, Q4/P4 or Q5/P5) ( $p>0,05)$ (Figure 6). Almost all experiments reveal $p$-values above the cut-off value of $0,05(p>0,05)$, which means that $\mathrm{HO}$ proposition is valid. The results obtained from Examiner F, sensors Q1/P1 and Q5/P5, were not considered significant, as sphericity principle was not verified (Table 3). Thus, it is concluded the mean bite pressure (psi) measured at different time frames is consistently the same, showing the high reproducibility of the measurements.
Comparison C - Testing the Differences between Sensors

(Q1/P1 versus Q2/P2 versus Q3/P3 versus Q4/P4 versus Q5/P5) The statistical comparison between the five FSS sensors (Q1/P1, Q2/P2, Q3/P3, Q4/P4 and Q5/P5) regarding the measurement of mean bite pressure (psi) was performed using a One-Way ANOVA for the different examiners $\mathrm{F}$ and $\mathrm{C}$ at the three different time moments (Time 0, Time 1 and Time 2).

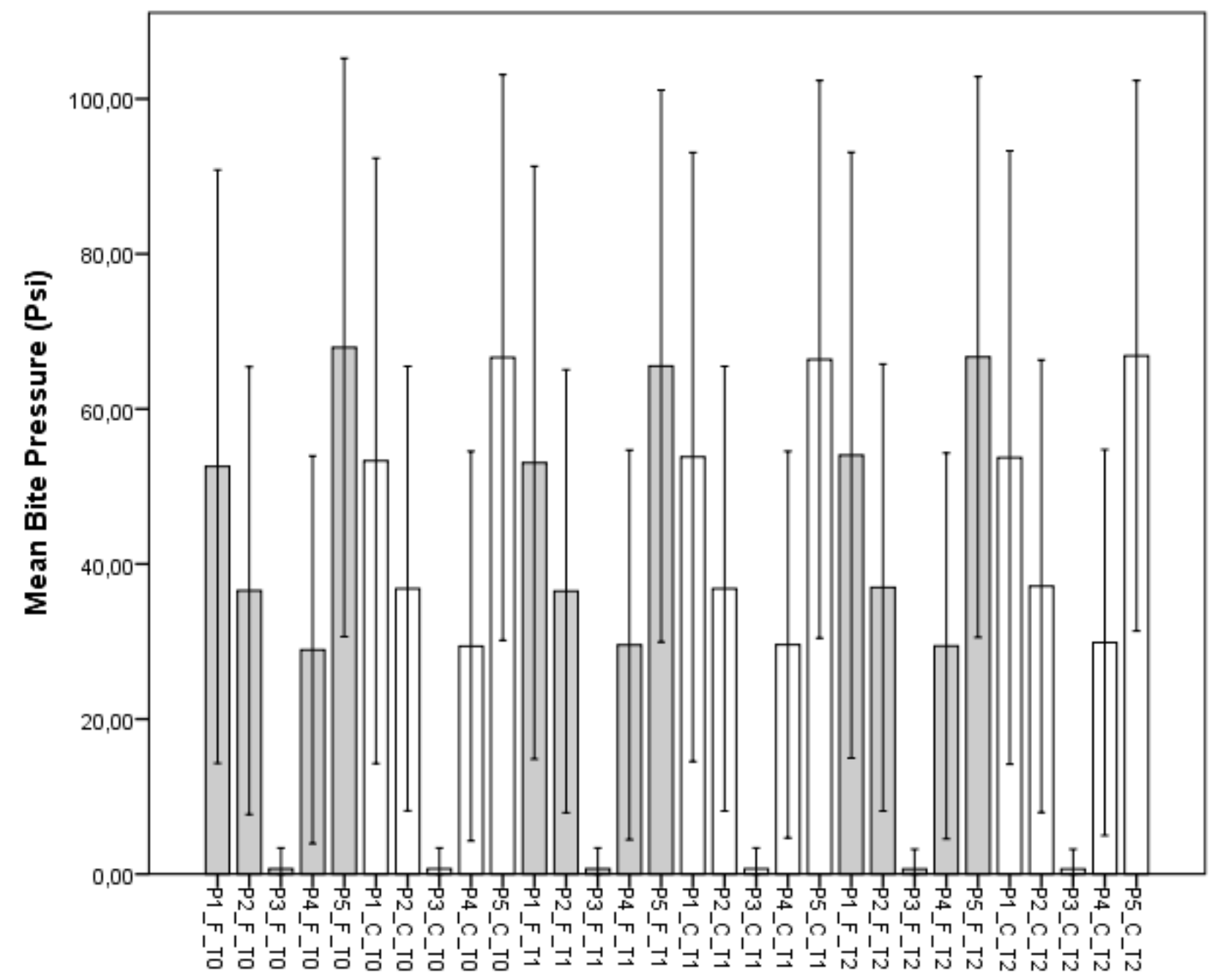

Figure 7. Mean bite pressure (psi) measured in five FSS sensors (Q1/P1, Q2/P2, Q3/P3, Q4/P4 and Q5/P5) by Examiner F and Examiner C at three different time moments (Time 0 , Time 1 and Time 2). Error bars represent standard deviation values. 
Table 4. Statistical parameters obtained in the One-Way ANOVA for the comparison of FSS sensors (Q1/P1, Q2/P2, Q3/P3, Q4/P4 and Q5/P5) when measuring the mean bite pressure (psi) in different experimental conditions.

\begin{tabular}{|c|c|c|c|c|c|c|}
\hline \multicolumn{2}{|c|}{ Sensors Comparison } & $\begin{array}{l}\text { Sum of } \\
\text { Squares }\end{array}$ & $\begin{array}{l}\text { Degrees of } \\
\text { Freedom (df) }\end{array}$ & Mean Square & $\begin{array}{c}\text { Test statistic } \\
\text { (F) }\end{array}$ & P-value (Sig) \\
\hline \multirow{3}{*}{$\begin{array}{l}\text { P1 vs } P 2 \text { vs } P 3 \text { vs } P 4 \text { vs } \\
\text { P5, Examiner F, Time } 0\end{array}$} & Between Groups & 77446,893 & 4,000 & 19361,723 & \multirow{3}{*}{22,403} & \multirow{3}{*}{$0,000^{*}$} \\
\hline & Within Groups & 125316,767 & 145,000 & 864,254 & & \\
\hline & Total & 202763,660 & 149,000 & - & & \\
\hline \multirow{3}{*}{$\begin{array}{l}\text { P1 vs } P 2 \text { vs } P 3 \text { vs } P 4 \text { vs } \\
\text { P5, Examiner F, Time } 1\end{array}$} & Between Groups & 73363,693 & 4,000 & 18340,923 & \multirow{3}{*}{21,931} & \multirow{3}{*}{$0,000^{*}$} \\
\hline & Within Groups & 121264,500 & 145,000 & 836,307 & & \\
\hline & Total & 194628,193 & 149,000 & - & & \\
\hline \multirow{3}{*}{$\begin{array}{l}\text { P1 vs } P 2 \text { vs } P 3 \text { vs } P 4 \text { vs } \\
\text { P5, Examiner F, Time } 2\end{array}$} & Between Groups & 76440,693 & 4,000 & 19110,173 & \multirow{3}{*}{22,265} & \multirow{3}{*}{$0,000^{*}$} \\
\hline & Within Groups & 124454,267 & 145,000 & 858,305 & & \\
\hline & Total & 200894,960 & 149,000 & - & & \\
\hline \multirow{3}{*}{$\begin{array}{l}\text { P1 vs } \mathrm{P} 2 \text { vs } \mathrm{P} 3 \text { vs } \mathrm{P} 4 \text { vs } \\
\text { P5, Examiner } \mathrm{C} \text {, Time } 1\end{array}$} & Between Groups & 75558,160 & 4,000 & 18889,540 & \multirow{3}{*}{21,890} & \multirow{3}{*}{$0,000^{*}$} \\
\hline & Within Groups & 125122,933 & 145,000 & 862,917 & & \\
\hline & Total & 200681,093 & 149,000 & - & & \\
\hline \multirow{3}{*}{$\begin{array}{l}\text { P1 vs } P 2 \text { vs } P 3 \text { vs } P 4 \text { vs } \\
\text { P5, Examiner C, Time } 2\end{array}$} & Between Groups & 75539,667 & 4,000 & 18884,917 & \multirow{3}{*}{22,027} & \multirow{3}{*}{$0,000^{*}$} \\
\hline & Within Groups & 124317,667 & 145,000 & 857,363 & & \\
\hline & Total & 199857,333 & 149,000 & - & & \\
\hline \multirow{3}{*}{$\begin{array}{l}\text { P1 vs } P 2 \text { vs P3 vs P4 vs } \\
\text { P5, Examiner C, Time } 3\end{array}$} & Between Groups & 76227,040 & 4,000 & 19056,760 & \multirow{3}{*}{22,140} & \multirow{3}{*}{$0,000^{*}$} \\
\hline & Within Groups & 124804,933 & 145,000 & 860,724 & & \\
\hline & Total & 201031,973 & 149,000 & - & & \\
\hline
\end{tabular}

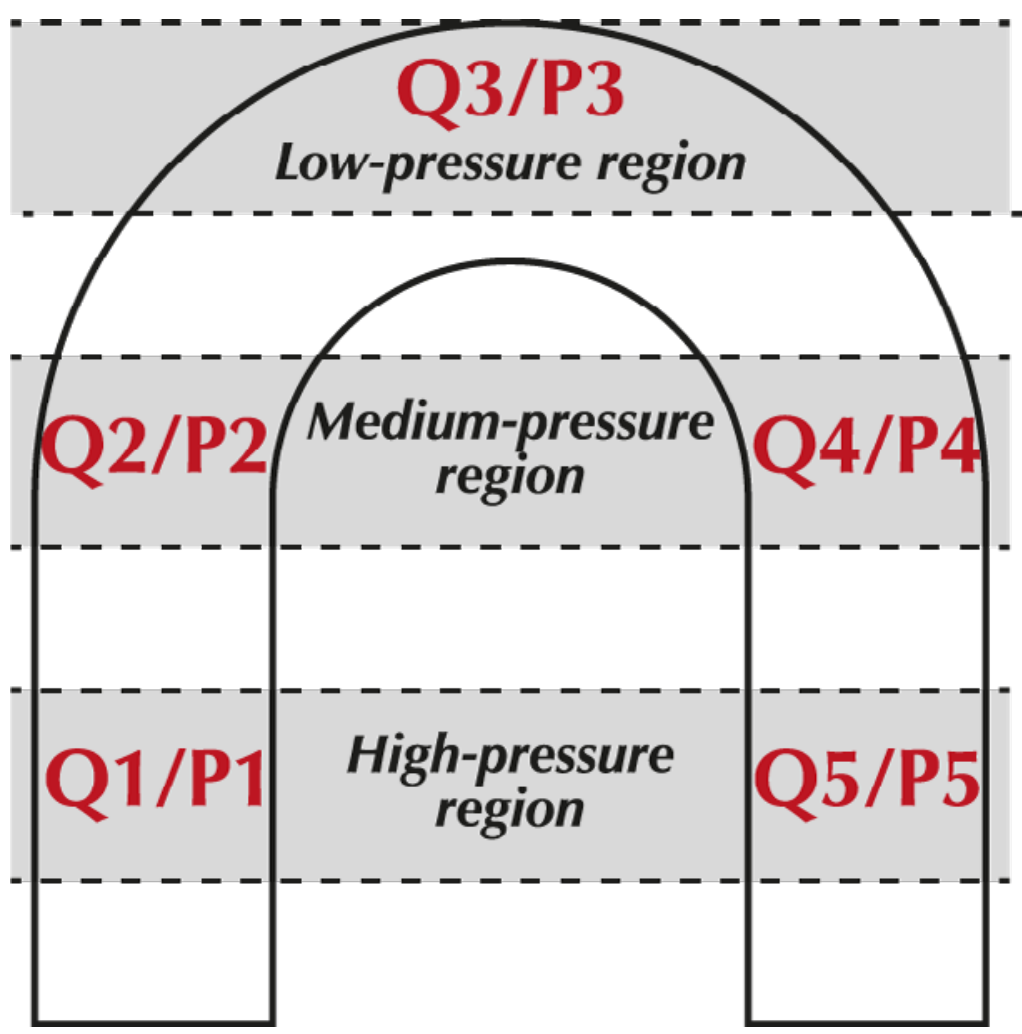

Figure 8. Three-pressure region model for dental occlusion. 
Table 5. Statistical parameters obtained in the Post-Hoc Gabriel test for the comparison of FSS sensors (Q1/P1, Q2/P2, Q3/P3, Q4/P4 and Q5/P5) when measuring the mean bite pressure (psi) in different experimental conditions.

\begin{tabular}{|c|c|c|c|c|c|}
\hline \multicolumn{3}{|c|}{ Dependent Variable } & $\begin{array}{c}\text { Mean } \\
\text { Difference } \\
(\mathrm{I}-\mathrm{J})\end{array}$ & $\begin{array}{l}\text { Std. } \\
\text { Error }\end{array}$ & Sig. \\
\hline \multirow{20}{*}{ F_TO } & \multirow{4}{*}{ Q1/P1 } & Q2/P2 & 16,000 & 7,591 & 0,308 \\
\hline & & Q3/P3 & $51,867^{\star}$ & 7,591 & 0,000 \\
\hline & & Q4/P4 & $23,633^{*}$ & 7,591 & 0,022 \\
\hline & & Q5/P5 & $-15,367$ & 7,591 & 0,363 \\
\hline & \multirow{4}{*}{ Q2/P2 } & $\mathrm{Q} 1 / \mathrm{P} 1$ & $-16,000$ & 7,591 & 0,308 \\
\hline & & Q3/P3 & $35,867^{\star}$ & 7,591 & 0,000 \\
\hline & & Q4/P4 & 7,633 & 7,591 & 0,976 \\
\hline & & Q5/P5 & $-31,367^{\star}$ & 7,591 & 0,001 \\
\hline & \multirow{4}{*}{ Q3/P3 } & $\mathrm{Q} 1 / \mathrm{P} 1$ & $-51,867^{*}$ & 7,591 & 0,000 \\
\hline & & $\mathrm{Q} 2 / \mathrm{P} 2$ & $-35,867^{\star}$ & 7,591 & 0,000 \\
\hline & & Q4/P4 & $-28,233^{*}$ & 7,591 & 0,003 \\
\hline & & Q5/P5 & $-67,233^{*}$ & 7,591 & 0,000 \\
\hline & \multirow{4}{*}{ Q4/P4 } & $\mathrm{Q} 1 / \mathrm{P} 1$ & $-23,633^{*}$ & 7,591 & 0,022 \\
\hline & & Q2/P2 & $-7,633$ & 7,591 & 0,976 \\
\hline & & Q3/P3 & $28,233^{*}$ & 7,591 & 0,003 \\
\hline & & Q5/P5 & $-39,000^{*}$ & 7,591 & 0,000 \\
\hline & \multirow{4}{*}{ Q5/P5 } & $\mathrm{Q} 1 / \mathrm{P} 1$ & 15,367 & 7,591 & 0,363 \\
\hline & & $\mathrm{Q} 2 / \mathrm{P} 2$ & $31,367^{*}$ & 7,591 & 0,001 \\
\hline & & Q3/P3 & $67,233^{*}$ & 7,591 & 0,000 \\
\hline & & Q4/P4 & $39,000^{*}$ & 7,591 & 0,000 \\
\hline \multirow{20}{*}{ F_T1 } & \multirow{4}{*}{ Q1/P1 } & $\mathrm{Q} 2 / \mathrm{P} 2$ & 16,567 & 7,467 & 0,245 \\
\hline & & Q3/P3 & $52,367^{\star}$ & 7,467 & 0,000 \\
\hline & & Q4/P4 & $23,500^{\star}$ & 7,467 & 0,020 \\
\hline & & Q5/P5 & $-12,467$ & 7,467 & 0,633 \\
\hline & \multirow{4}{*}{ Q2/P2 } & $\mathrm{Q} 1 / \mathrm{P} 1$ & $-16,567$ & 7,467 & 0,245 \\
\hline & & Q3/P3 & $35,800^{*}$ & 7,467 & 0,000 \\
\hline & & Q4/P4 & 6,933 & 7,467 & 0,986 \\
\hline & & Q5/P5 & $-29,033^{*}$ & 7,467 & 0,002 \\
\hline & \multirow{4}{*}{ Q3/P3 } & $\mathrm{Q} 1 / \mathrm{P} 1$ & $-52,367^{\star}$ & 7,467 & 0,000 \\
\hline & & $\mathrm{Q} 2 / \mathrm{P} 2$ & $-35,800^{*}$ & 7,467 & 0,000 \\
\hline & & Q4/P4 & $-28,867^{\star}$ & 7,467 & 0,002 \\
\hline & & Q5/P5 & $-64,833^{*}$ & 7,467 & 0,000 \\
\hline & \multirow{4}{*}{ Q4/P4 } & $\mathrm{Q} 1 / \mathrm{P} 1$ & $-23,500^{*}$ & 7,467 & 0,020 \\
\hline & & $\mathrm{Q} 2 / \mathrm{P} 2$ & $-6,933$ & 7,467 & 0,986 \\
\hline & & Q3/P3 & $28,867^{\star}$ & 7,467 & 0,002 \\
\hline & & Q5/P5 & $-35,967^{\star}$ & 7,467 & 0,000 \\
\hline & \multirow{4}{*}{ Q5/P5 } & $\mathrm{Q} 1 / \mathrm{P} 1$ & 12,467 & 7,467 & 0,633 \\
\hline & & $\mathrm{Q} 2 / \mathrm{P} 2$ & $29,033^{*}$ & 7,467 & 0,002 \\
\hline & & Q3/P3 & $64,833^{\star}$ & 7,467 & 0,000 \\
\hline & & Q4/P4 & $35,967^{*}$ & 7,467 & 0,000 \\
\hline
\end{tabular}

\begin{tabular}{|c|c|c|c|c|c|}
\hline \multicolumn{3}{|c|}{ Dependent Variable } & $\begin{array}{c}\text { Mean } \\
\text { Difference } \\
(\mathrm{I}-\mathrm{J})\end{array}$ & $\begin{array}{l}\text { Std. } \\
\text { Error }\end{array}$ & sig. \\
\hline \multirow{20}{*}{ C_TO } & \multirow{4}{*}{ Q1/P1 } & $\mathrm{Q} 2 / \mathrm{P} 2$ & 16,467 & 7,585 & 0,271 \\
\hline & & Q3/P3 & $52,600^{*}$ & 7,585 & 0,000 \\
\hline & & Q4/P4 & $23,900^{*}$ & 7,585 & 0,020 \\
\hline & & Q5/P5 & $-13,333$ & 7,585 & 0,563 \\
\hline & \multirow{4}{*}{ Q2/P2 } & $\mathrm{Q} 1 / \mathrm{P} 1$ & $-16,467$ & 7,585 & 0,271 \\
\hline & & Q3/P3 & $36,133^{*}$ & 7,585 & 0,000 \\
\hline & & Q4/P4 & 7,433 & 7,585 & 0,980 \\
\hline & & Q5/P5 & $-29,800^{*}$ & 7,585 & 0,001 \\
\hline & \multirow{4}{*}{ Q3/P3 } & $\mathrm{Q} 1 / \mathrm{P} 1$ & $-52,600^{*}$ & 7,585 & 0,000 \\
\hline & & $\mathrm{Q} 2 / \mathrm{P} 2$ & $-36,133^{*}$ & 7,585 & 0,000 \\
\hline & & Q4/P4 & $-28,700^{*}$ & 7,585 & 0,002 \\
\hline & & Q5/P5 & $-65,933^{*}$ & 7,585 & 0,000 \\
\hline & \multirow{4}{*}{ Q4/P4 } & $\mathrm{Q} 1 / \mathrm{P} 1$ & $-23,900^{*}$ & 7,585 & 0,020 \\
\hline & & $\mathrm{Q} 2 / \mathrm{P} 2$ & $-7,433$ & 7,585 & 0,980 \\
\hline & & Q3/P3 & $28,700^{*}$ & 7,585 & 0,002 \\
\hline & & Q5/P5 & $-37,233^{\star}$ & 7,585 & 0,000 \\
\hline & \multirow{4}{*}{ Q5/P5 } & Q1/P1 & 13,333 & 7,585 & 0,563 \\
\hline & & Q2/P2 & $29,800^{*}$ & 7,585 & 0,001 \\
\hline & & Q3/P3 & $65,933^{*}$ & 7,585 & 0,000 \\
\hline & & Q4/P4 & $37,233^{*}$ & 7,585 & 0,000 \\
\hline \multirow{20}{*}{ C_T1 } & \multirow{4}{*}{ Q1/P1 } & $\mathrm{Q} 2 / \mathrm{P} 2$ & 16,967 & 7,560 & 0,231 \\
\hline & & Q3/P3 & $53,100^{*}$ & 7,560 & 0,000 \\
\hline & & Q4/P4 & $24,200^{*}$ & 7,560 & 0,017 \\
\hline & & Q5/P5 & $-12,600$ & 7,560 & 0,635 \\
\hline & \multirow{4}{*}{ Q2/P2 } & $\mathrm{Q} 1 / \mathrm{P} 1$ & $-16,967$ & 7,560 & 0,231 \\
\hline & & Q3/P3 & $36,133^{*}$ & 7,560 & 0,000 \\
\hline & & Q4/P4 & 7,233 & 7,560 & 0,983 \\
\hline & & Q5/P5 & $-29,567^{*}$ & 7,560 & 0,001 \\
\hline & \multirow{4}{*}{ Q3/P3 } & $\mathrm{Q} 1 / \mathrm{P} 1$ & $-53,100^{*}$ & 7,560 & 0,000 \\
\hline & & $\mathrm{Q} 2 / \mathrm{P} 2$ & $-36,133^{*}$ & 7,560 & 0,000 \\
\hline & & $\mathrm{Q} 4 / \mathrm{P} 4$ & $-28,900^{*}$ & 7,560 & 0,002 \\
\hline & & Q5/P5 & $-65,700^{*}$ & 7,560 & 0,000 \\
\hline & \multirow{4}{*}{ Q4/P4 } & $\mathrm{Q} 1 / \mathrm{P} 1$ & $-24,200^{*}$ & 7,560 & 0,017 \\
\hline & & $\mathrm{Q} 2 / \mathrm{P} 2$ & $-7,233$ & 7,560 & 0,983 \\
\hline & & Q3/P3 & $28,900^{*}$ & 7,560 & 0,002 \\
\hline & & Q5/P5 & $-36,800^{*}$ & 7,560 & 0,000 \\
\hline & \multirow{4}{*}{ Q5/P5 } & $\mathrm{Q} 1 / \mathrm{P} 1$ & 12,600 & 7,560 & 0,635 \\
\hline & & Q2/P2 & $29,567^{\star}$ & 7,560 & 0,001 \\
\hline & & Q3/P3 & $65,700^{*}$ & 7,560 & 0,000 \\
\hline & & Q4/P4 & $36,800^{*}$ & 7,560 & 0,000 \\
\hline
\end{tabular}




\begin{tabular}{|c|c|c|c|c|c|}
\hline \multicolumn{3}{|c|}{ Dependent Variable } & \multirow{2}{*}{$\begin{array}{c}\begin{array}{c}\text { Mean } \\
\text { Difference } \\
(\mathbf{I}-\mathrm{J})\end{array} \\
17,067\end{array}$} & \multirow{2}{*}{$\begin{array}{c}\text { Std. } \\
\text { Error } \\
7,564\end{array}$} & \multirow{2}{*}{$\begin{array}{l}\text { Sig. } \\
0,225\end{array}$} \\
\hline \multirow{20}{*}{$F_{-} T 2$} & \multirow{4}{*}{ Q1/P1 } & $\mathrm{Q} 2 / \mathrm{P} 2$ & & & \\
\hline & & Q3/P3 & $53,367^{*}$ & 7,564 & 0,000 \\
\hline & & Q4/P4 & $24,600^{*}$ & 7,564 & 0,014 \\
\hline & & Q5/P5 & $-12,667$ & 7,564 & 0,629 \\
\hline & \multirow{4}{*}{ Q2/P2 } & $\mathrm{Q} 1 / \mathrm{P} 1$ & $-17,067$ & 7,564 & 0,225 \\
\hline & & Q3/P3 & $36,300^{*}$ & 7,564 & 0,000 \\
\hline & & Q4/P4 & 7,533 & 7,564 & 0,977 \\
\hline & & Q5/P5 & $-29,733^{\star}$ & 7,564 & 0,001 \\
\hline & \multirow{4}{*}{ Q3/P3 } & $\mathrm{Q} 1 / \mathrm{P} 1$ & $-53,367^{\star}$ & 7,564 & 0,000 \\
\hline & & Q2/P2 & $-36,300^{*}$ & 7,564 & 0,000 \\
\hline & & Q4/P4 & $-28,767^{*}$ & 7,564 & 0,002 \\
\hline & & Q5/P5 & $-66,033^{*}$ & 7,564 & 0,000 \\
\hline & \multirow{4}{*}{ Q4/P4 } & $\mathrm{Q} 1 / \mathrm{P} 1$ & $-24,600^{*}$ & 7,564 & 0,014 \\
\hline & & $\mathrm{Q} 2 / \mathrm{P} 2$ & $-7,533$ & 7,564 & 0,977 \\
\hline & & Q3/P3 & $28,76667^{*}$ & 7,564 & 0,002 \\
\hline & & Q5/P5 & $-37,26667^{*}$ & 7,564 & 0,000 \\
\hline & \multirow{4}{*}{ Q5/P5 } & $\mathrm{Q} 1 / \mathrm{P} 1$ & 12,667 & 7,564 & 0,629 \\
\hline & & Q2/P2 & $29,73333^{*}$ & 7,564 & 0,001 \\
\hline & & Q3/P3 & $66,03333^{*}$ & 7,564 & 0,000 \\
\hline & & Q4/P4 & $37,26667^{\star}$ & 7,564 & 0,000 \\
\hline
\end{tabular}

\begin{tabular}{|c|c|c|c|c|c|}
\hline \multicolumn{3}{|c|}{ Dependent Variable } & $\begin{array}{c}\text { Mean } \\
\text { Difference } \\
(\mathrm{I}-\mathrm{J})\end{array}$ & $\begin{array}{l}\text { Std. } \\
\text { Error }\end{array}$ & Sig. \\
\hline \multirow{20}{*}{ C_T2 } & \multirow{4}{*}{ Q1/P1 } & Q2/P2 & 16,600 & 7,575 & 0,259 \\
\hline & & Q3/P3 & $53,067^{*}$ & 7,575 & 0,000 \\
\hline & & Q4/P4 & $23,867^{\star}$ & 7,575 & 0,020 \\
\hline & & Q5/P5 & $-13,133$ & 7,575 & 0,582 \\
\hline & \multirow{4}{*}{ Q2/P2 } & $\mathrm{Q} 1 / \mathrm{P} 1$ & $-16,600$ & 7,575 & 0,259 \\
\hline & & Q3/P3 & $36,467^{\star}$ & 7,575 & 0,000 \\
\hline & & Q4/P4 & 7,267 & 7,575 & 0,983 \\
\hline & & Q5/P5 & $-29,733^{*}$ & 7,575 & 0,001 \\
\hline & \multirow{4}{*}{ Q3/P3 } & Q1/P1 & $-53,067^{*}$ & 7,575 & 0,000 \\
\hline & & Q2/P2 & $-36,467^{*}$ & 7,575 & 0,000 \\
\hline & & Q4/P4 & $-29,200^{*}$ & 7,575 & 0,002 \\
\hline & & Q5/P5 & $-66,200^{*}$ & 7,575 & 0,000 \\
\hline & \multirow{4}{*}{ Q4/P4 } & Q1/P1 & $-23,867^{\star}$ & 7,575 & 0,020 \\
\hline & & Q2/P2 & $-7,267$ & 7,575 & 0,983 \\
\hline & & Q3/P3 & $29,20000^{*}$ & 7,575 & 0,002 \\
\hline & & Q5/P5 & $-37,00000^{*}$ & 7,575 & 0,000 \\
\hline & \multirow{4}{*}{ Q5/P5 } & Q1/P1 & 13,133 & 7,575 & 0,582 \\
\hline & & Q2/P2 & $29,73333^{*}$ & 7,575 & 0,001 \\
\hline & & Q3/P3 & $66,20000^{*}$ & 7,575 & 0,000 \\
\hline & & Q4/P4 & $37,00000^{*}$ & 7,575 & 0,000 \\
\hline
\end{tabular}


There are significant differences in the mean bite pressure (psi) measured by the different FSS sensors (Q1/P1, Q2/P2, Q3/P3, Q4/P4 and Q5/P5), when the measurement is made in the same experimental conditions (Figure 7 and Table 4). All experiments reveal $p$-values below the cut-off value of $0,05(p<0,05)$, which means that $\mathrm{HO}$ proposition is invalid. Thus, it is concluded that the five FSS sensors detect different mean bite pressures (psi) for the same Examiner ( $\mathrm{F}$ or $\mathrm{C}$ ) at the same time moment (Time 0 , Time 1 or Time 2).

Because One-Way ANOVA only gives information about the presence of differences, not specifying where these differences are located, a Post-hoc Gabriel test was used to perform pairwise comparisons between the FSS sensors, and these results are represented in Table 5.

Significant differences $(p<0,05)$ have been identified between certain pairs of FSS sensors (Table 5), allowing the definition of a three-pressure region model (Figure 8): 1) low-pressure region located in the anterior part of the dental arch;2) mediumpressure region in the intermediate part of the dental arch; and 3) high-pressure region located in the posterior part of the dental arch.

Another interesting observation is that, when two FSS sensors are located in the same pressure region (i.e., Q1/P1+Q5/P5 and $\mathrm{Q} 2 / \mathrm{P} 2+\mathrm{Q} 4 / \mathrm{P} 4)$, no statistical differences are recognisable within the pairs of FSS sensors, meaning that the pressures detected are statistically identical to one another $(p>0,05)$.

On the opposite side, whenever two FSS sensors are located in different pressure regions, statistically significant differences $(p<$ 0,05 ) have been found between the measured pressures (Figure 8 and Table 5), showing the high sensibility of measurement of the experimental device.

\section{CONCLUSIONS}

The piezoelectric sensors used in the present study have shown high reproducibility of measurement. Neither the variation of examiner, nor the variation of time have shown to influence the bite pressure (psi).

In contrast, the occlusal force measurement system developed has shown a high level of sensitivity due to the distribution of the five FSS sensors in the horseshoe-shaped form.

A three-pressure region model fits the experimental data shown in this study, comprising a low-pressure region located in the anterior part of the dental arch, a medium-pressure region in the medial part of the dental arch and an high-pressure region located in the posterior part of the dental arch.

Due to the recent miniaturization of FSS sensors, the authors are developing new occlusal force measurement systems comprising a higher number of piezoelectric sensors, with the objective of attaining even higher sensitivity of measurement throughout the different region of the dental arches.

\section{CONFLICT OF INTEREST}

The authors declared that there is no conflict of interest.

\section{REFERENCES}

1. Ellis E 3rd, Throckmorton GS, Sinn DP. Bite forces before and after surgical correction of mandibular prognathism. J Oral Maxillofac Surg. 1996 Feb;54(2):176-81.

2. Harada K, Watanabe M, Ohkura K, Enomoto S. Measure of bite force and occlusal contact area before and after bilateral sagittal split ramus osteotomy of the mandible using a new pressure-sensitive device: a preliminary report. J Oral Maxillofac Surg. 2000 Apr;58(4):370-3; discussion 373

3. Iwase M, Sugimori M, Kurachi Y, Nagumo M. Changes in bite force and occlusal contacts in patients treated for mandibular prognathism by orthognathic surgery. J Oral Maxillofac Surg. 1998 Jul;56(7):850-5; discussion 855-6.

4. Kikuta T, Hara I, Seto T, Yoshioka I, Nakashima T, Yasumitsu C. Evaluation of masticatory function after sagittal split ramus osteotomy for patients with mandibular prognathism. Int J Adult Orthodon Orthognath Surg. 1994;9(1):9-17.

5. Kim YG, Oh SH. Effect of mandibular setback surgery on occlusal force. J Oral Maxillofac Surg. 1997 Feb;55(2):121-6; discussion 126-8.

6. Kobayashi T, Honma K, Nakajima T, Hanada K. Masticatory function in patients with mandibular prognathism before and after orthognathic surgery. J Oral Maxillofac Surg. 1993 Sep;51(9):997-1001; discussion 1002-3.

7. Kobayashi T, Honma K, Shingaki S, Nakajima T. Changes in masticatory function after orthognathic treatment in patients with mandibular prognathism. Br J Oral Maxillofac Surg. 2001 Aug;39(4):260-5.

8. Nagai I, Tanaka N, Noguchi M, Suda Y, Sonoda T, Kohama G. Changes in occlusal state of patients with mandibular prognathism after orthognathic surgery: a pilot study. Br J Oral Maxillofac Surg. 2001 Dec;39(6):429-33.

9. Ohkura K, Harada K, Morishima S, Enomoto S. Changes in bite force and occlusal contact area after orthognathic surgery for correction of mandibular prognathism. Oral Surg Oral Med Oral Pathol Oral Radiol Endod. 2001 Feb;91(2):141-5.

10. Proffit WR, Turvey TA, Fields HW, Phillips C. The effect of orthognathic surgery on occlusal force. J Oral Maxillofac Surg. 1989 May;47(5):457-63.

11. Raustia AM, Oikarinen KS. Changes in electric activity of masseter and temporal muscles after mandibular sagittal split osteotomy. Int J Oral Maxillofac Surg. 1994 Jun;23(3):180-4.

12. Shiratsuchi Y, Kouno K, Tashiro H. Evaluation of masticatory function following orthognathic surgical correction of mandibular prognathism. J Craniomaxillofac Surg. 1991 Oct;19(7):299-303.

13. Throckmorton GS, Buschang PH, Ellis E 3rd. Improvement of maximum occlusal forces after orthognathic surgery. J Oral Maxillofac Surg. 1996 Sep;54(9):1080-6.

14. Tate GS, Throckmorton GS, Ellis E 3rd, Sinn DP. Masticatory performance, muscle activity, and occlusal force in preorthognathic surgery patients. J Oral Maxillofac Surg. 1994 May;52(5):476-81; discussion 482. d

15. Thomas GP, Throckmorton GS, Ellis E 3rd, Sinn DP. The effects of orthodontic treatment on isometric bite forces and mandibular motion in patients before orthognathic surgery. J Oral Maxillofac Surg. 1995 Jun;53(6):673-8; discussion 678-9.

16. Matsui Y, Ohno K, Michi K, Suzuki Y, Yamagata K. A computerized method for evaluating balance of occlusal load. J Oral Rehabil. 1996 Aug;23(8):530-5.

17. Suzuki T, Kumagai H, Watanabe T, Uchida T, Nagao M. Evaluation of complete denture occlusal contacts using pressure-sensitive sheets. Int J Prosthodont. 1997 Jul-Aug;10(4):386-91.

18. Matsui Y, Neukam FW, Wichmann M, Ohno K. A computerized method for evaluating distribution of occlusal load on implant-supported fixed cantilever prostheses. Int J Oral Maxillofac Implants. 1996 Jan-Feb;11(1):67-72.

19. Matsui Y, Neukam FW, Schmelzeisen R, Ohno K. Masticatory function of postoperative tumor patients rehabilitated with osseointegrated implants. J Oral Maxillofac Surg. 1996 Apr;54(4):441-7.

20. Hayakawa I, Watanabe I, Hirano S, Nagao M, Seki T. A simple method for evaluating masticatory performance using a color-changeable chewing gum. Int J Prosthodont. 1998 Mar-Apr;11(2):173-6 